\title{
Designing of english challenge mobile game application as the media of english language learning
}

\author{
Vito Pratama Putra Setyadharma ${ }^{1 *}$, Emi Iryanti ${ }^{1}$, Indra Hidayatulloh ${ }^{2}$, Novanda Alim Setya Nugraha ${ }^{1}$ \\ ${ }^{1}$ Institut Teknologi Telkom Purwokerto, 53147 Banyumas, Central Java, Indonesia \\ ${ }^{2}$ Universitas Negeri Yogyakarta, 55281 Yogyakarta, Indonesia \\ *E-mail: vitopratama95@gmail.com \\ * corresponding author
}

ABSTRACT

English became the first foreign language that came to Indonesia in 1967. The human needs of English can already be seen through lots of official scientific works in English and its intense competitions globally. However, still, many people find it difficult to learn English, for example, the difficulty in understanding tenses, differences between writing, reading, and pronouncing. By relying on the latest features on a smartphone, which in the meantime, the smartphone is one of many gadgets that is the most practical to use in anywhere and anytime, plus, with gaming contents as the best multimedia entertainer application, learning English will be more interactive and easier to use. In this research, Construct 2 is used as The Developer App and Game Development Life Cycle (GDLC) method of Rido Ramadan, and Yani Widyani's version is used as The Development Method. The game system tested by using a black box and by giving out a Questionnaire for User Interface Satisfaction to 24 respondents, to test the system's usability. It resulted in $80,83 \%$ for the whole of the system, meaning that the whole system is quite interesting in the respondents' view. Then, the screen display gained $80,41 \%$, this means that the screen display is very interesting and did not confuse the respondents. Technology and information games gained $75.41 \%$, this means that the information contained in the game is quite good, however, further, development is needed. The introduction of the game's system gained $71.63 \%$, which means that some of the system's ability did not run effectively and needed further repair and development. The last, usability and user interface gained $76.25 \%$, this means that the game is quite interactive to the respondents.

This is an open access article under the CC-BY-SA license.
ARTICLE INFO

\author{
Article history \\ Received: \\ 30 September 2020 \\ Revised: \\ 14 October 2020 \\ Accepted: \\ 14 October 2020 \\ Keywords \\ English \\ Learning \\ Game \\ Smartphone \\ GDLC
}

\section{Introduction}

The coming of English as a foreign language in Indonesia has been applied in the Dutch colonial era. However, the English language was officially applied to schools in Indonesia after the publication of the Ministry of Education and Cultures' acts in 1967 and has been developing since the facing of the millennium era by applying English in elementary schools [1]. 
Journal of Engineering and Applied Technology

Vol. 1, No. 1, March 2020, pp. 30-42

However, many stated that learning English is easy. According to English First's website in English proficiency Index, Indonesia is on the $39^{\text {th }}$ out of 80 countries in the whole world that uses English at a "Low' level [2]. If we pay attention to some parts of Indonesia, there are people in some areas that don't have the ability to speak English properly.

The difficulties in the English language are not only faced by Indonesia but also countries that the majority of the citizens speak English as their mother tongue. The principal of the City of Leeds School, Georgiana Sale, stated to BBC that, many of the students, who were born and raised in English speaking countries, that can't speak English properly. They have to be provided with English learning gradually to communicate in English properly [3].

The root of the issues is that there are so many tenses that the students have to memorize. Each of the tenses has its formula with different verbs, that confuses the students. In speaking English, even though the listener understood what the speaker said, sometimes, the tenses are not concerned. Whereas, tenses are very important, whether in writing or pronouncing. Not only that, not memorizing the alphabets, differences in reading and writing, and difficulties in pronouncing are also some parts of difficulties in speaking English [4].

With the latest technologies, many ways can be obtained in learning English well and easily understood. One of those is to learn English from the game application. Speaking of games, most of the game applications nowadays use English as the main language. However, it would be better if English language learning becomes the main theme of the game, and then combined with fun and challenging material such as games, this results in an education game that of course, gives the users ability to learn English with fun.

\section{Method}

\subsection{Literature Review}

In this stage, the main focus is on searching for information related to this research through journals, books, literature, and games. This literature review is done to review existed information as the base to create a new concept of this research and the initial concept of the game that is going to be designed.

\subsection{Data Collection}

The main focus of this stage is on the collecting of needed data that will be used as the material to create this game. The data that is needed are questions, stories, and other materials that are related to English learning.

\subsection{Game Design and Implementation}

In this stage, the method that was used is the GDLC method; Rido Ramadan dan Yani Widyani's version. Generally, there are 6 development steps in this method. Those are initiation, pre-production, production, testing, beta, and release [5]. In the design, the steps related are initiation and preproduction, which covers layout design, interface design, game-play system, game activity sequences, and story designs that will be inputted onto the game. On implementations, the steps related are production to testing. After the game design is made, an Internal system is made with Construct 2 as 
Journal of Engineering and Applied Technology

Vol. 1, No. 1, March 2020, pp. 30-42

the game system design, Adobe Illustrator as user interface design, and SAI paint tool as the character coloring design.

\subsection{Testing}

The main focus of this stage is on game testing. Associated with GDLC, this stage the beta stage of the game. Testing is done by giving out a questionnaire to specific users that already tried the game before. This stage is done to find the errors and bugs in the game.

\subsection{Test Result Analysis}

The main focus of this stage is on the questionnaire results checking and testing. New data about user satisfaction, errors, and bugs in the game can be obtained from the questionnaire results. The results of this analysis can be used to develop and to adjust the game in the future.

\section{Results and Discussion}

Before designing the game product, it is important to know the game concepts are needed first.

\subsection{High Concept Document}

The designing of the English challenge game is described in the High Concept Document, stated below.

(1) High Concept

In this game, the player will help Yuki in solving mysteries in a black and white world that she accidentally entered. Interestingly, the villagers in that world cannot speak, not even a word. She's accompanied by Teddy Bear she calls Kuma, however, she too, cannot speak or say any word just like the rest of the villagers. During the game, the player will be faced with an English question based on the grade chosen. When the player finished a stage, a scene of a continuous story will pop up. The more stages cleared, the stories that are revealed will be more intense until the mysteries of the black and white world are all revealed.

(2) Feature

Every stage contains a story, whether it is before the game or after the game-play. The player will be given three chances during the game.

(3) Player Motivation

The player will help Yuki to solve the mysteries in the black and white world by choosing stages and clearing given missions on every stage to continue to the next stage and to see the continuation of the story.

(4) Genre

English Challenge game is a Trivia game.

(5) Target Customer

Junior high school students and above.

(6) Competition

The implemented competition model is a single player.

(7) Unique Selling Points

Trivia game with questions about the English language. 
Journal of Engineering and Applied Technology

Vol. 1, No. 1, March 2020, pp. 30-42

(8) Target Hardware

Android is used as hardware.

(9) Design Goals

a) Simple: Game with simple rules and game styles and easy to understand.

b) Challenging: With variations of missions and time limits challenges the player to play the game.

(10) Character

a) Yuki Shirogane: Yuki is a girl that mysteriously stranded in a black and white world. Armed with the ability to speak English, known for her kind heart and helpful behavior, gets ready to reveal the mysteries and to bring back colors to the black and white world.

b) Kuma: A teddy bear in an army suit. He's one of the local villagers. Just like the rest of the villagers, he too, cannot speak. He can only say “Kuma!". With the help of Yuki, Kuma intends to solve the problems in his world.

(11) Rules

Each stage has different missions. With a minimum number of scores that must be completed by the player and/or the endurance of the player in answering the questions until the time runs out. Before the game starts, the player will be given three lives. One life will be gone if the player answered wrongly. And the player will lose if the lives run out.

\subsection{Use Case Diagram}

Users can do 5 things in this game. To see the story, it means that the user can see existing stories from the game that was made. To select "Stage", it means that the user can select the desired "stage" before starting the game. "Stage" here is material from "grade" that is selected and interrelated.

To see "Credit", it means that the user can see the menu with a list of names involved in making the game. To enter the gameplay system means that the user can directly access the gameplay to play. The Use Case Diagram is shown in Fig.1.

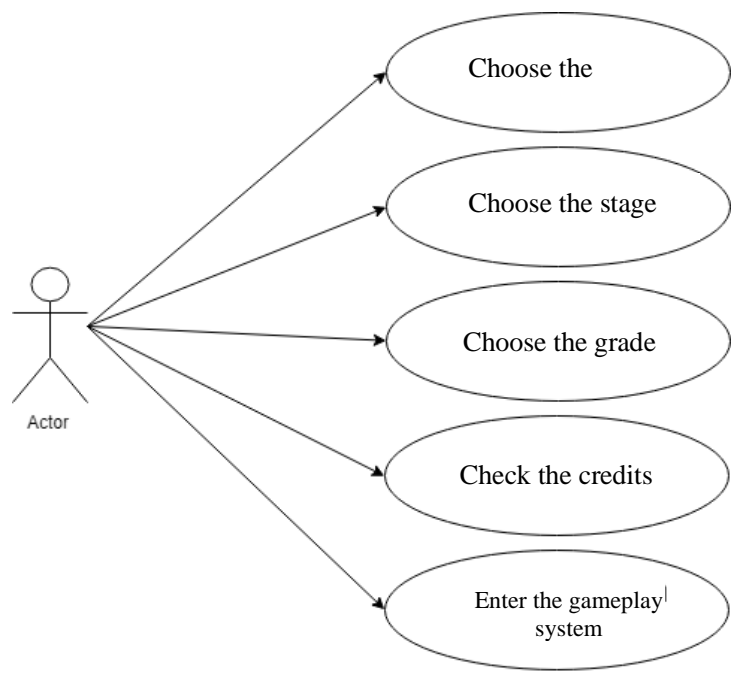

Fig.1. Use Case Diagram 


\subsection{Game Interface}

The results of English Challenge game display can be seen in the following pictures.

(1) Main menu Interface

This interface provides menu options for the player. There are 3 options provided. The "Start" button is the button that directs the player to start the game, the "Credits" button displays the list of names involved in making the game, and the "Quit" button directs the player to exit the application. The interface can be seen in Fig.2.

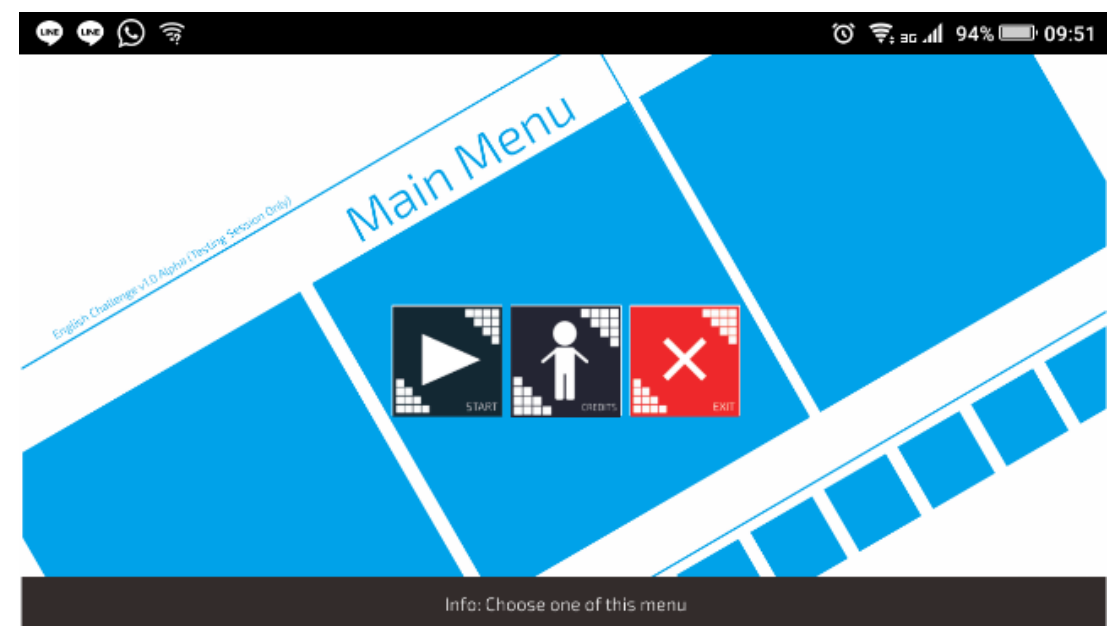

Fig.2. Main menu Interface

\section{(2) "Select Grade" Interface}

This interface provided stage options that will be chosen by the player. The grade is adjusted to the standard curriculum for junior high schools starting from grade 7 (easy) to grade 9 (difficult). Note that in the last 2 boxes there is the word "Coming Soon", which means the next 2 Grade will be updated later. It is presented in Fig.3.

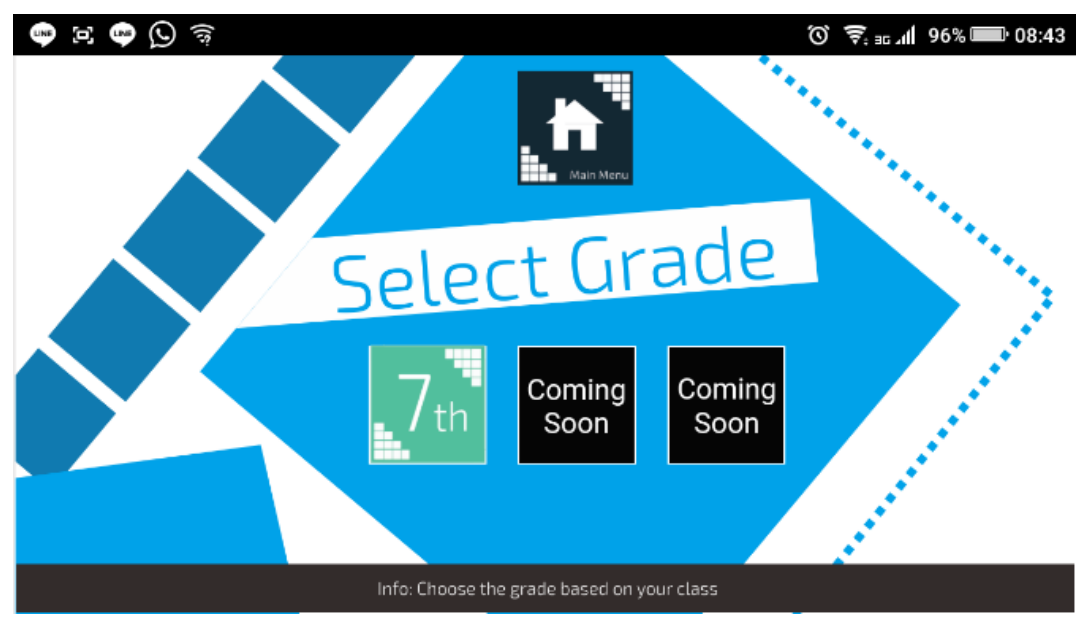

Fig.3. "Select Grade” Interface 
(3) "Select Stage" Interface

Fig.4. shows the "Select Stage' interface. This interface provides a choice of material to be selected by the player. Each material that is available is material based on the grade chosen by the previous player, and the entire material available has been adapted to the junior high school curriculum standard. Same as "Grade", the "Stage" menu is also filled with the "Coming Soon" box which will be updated in the future.

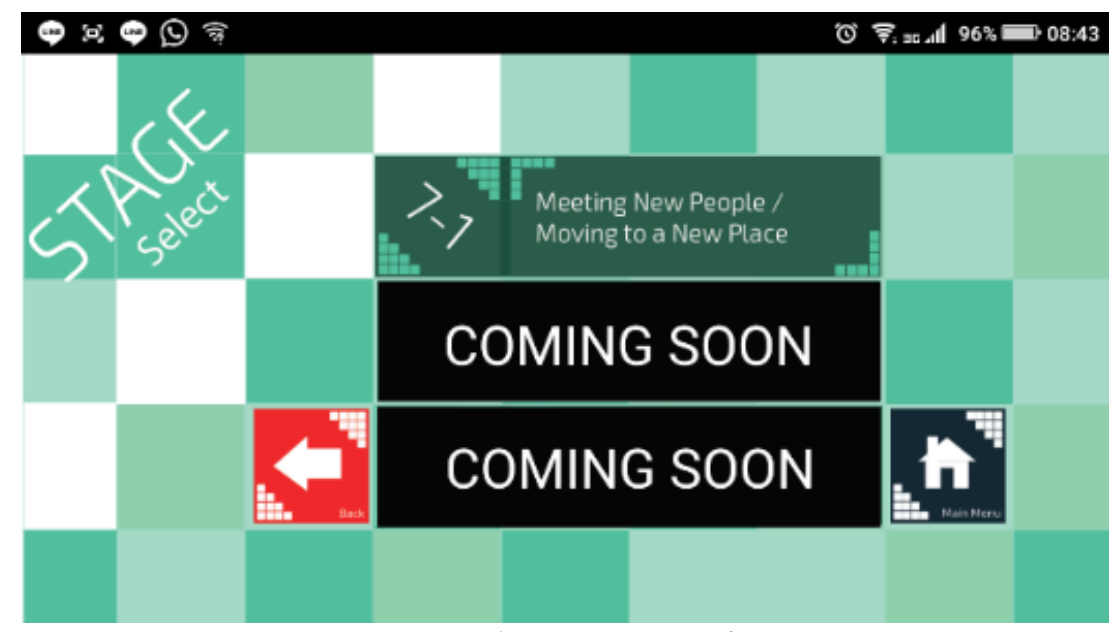

Fig.4. "Select Stage" Interface

(4) "Story" Interface

The "Story" Interface is illustrated in Fig.5. This interface provides stories that are closely related to the topic chosen by the player on the "Stage" Interface. Each stage provides a different story. The results of the Interface can be seen in the following figure.

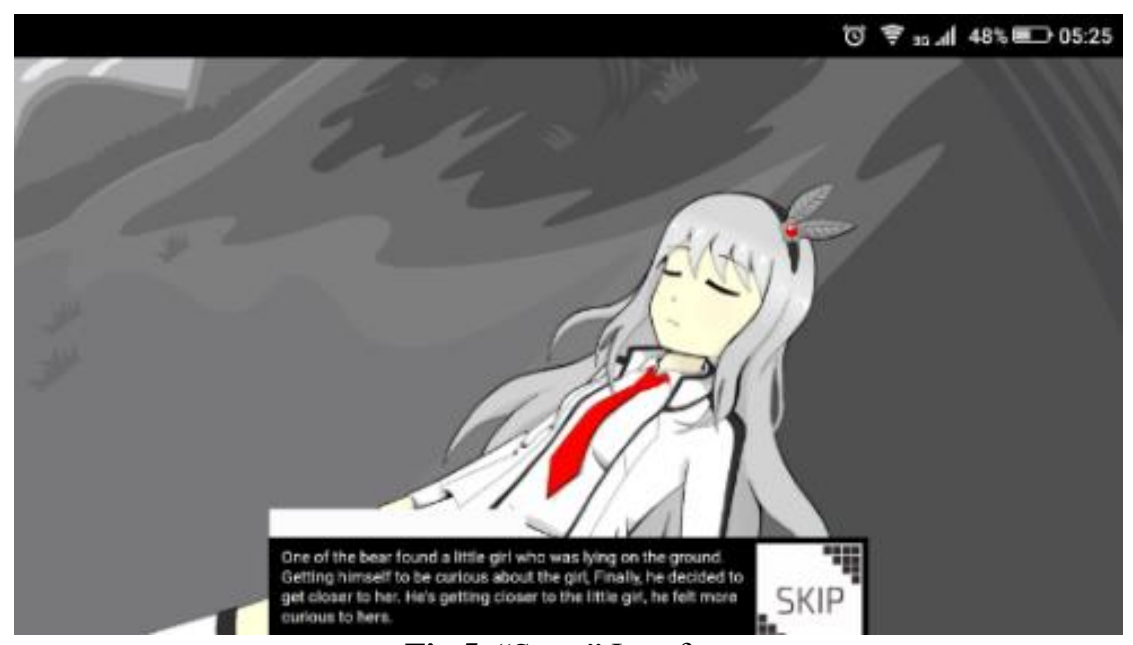

Fig.5. "Story" Interface 
Journal of Engineering and Applied Technology

Vol. 1, No. 1, March 2020, pp. 30-42

(5) "Loading" Interface

This interface functions more as a pause to move to the next layout. The description of the image can be seen in the following picture. This interface is presented in Fig.6.

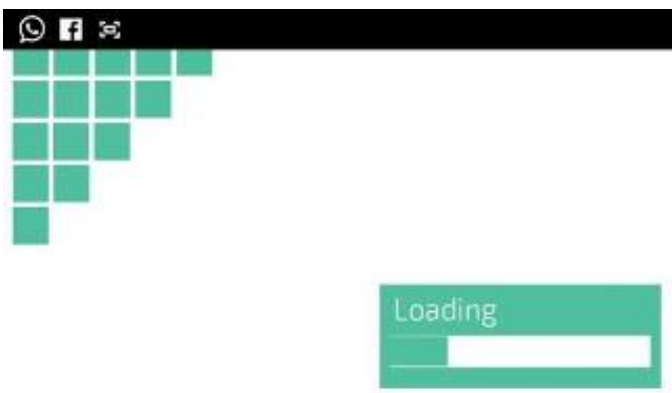

(6) "Mission" Interface

Fig.6. "Loading" Interface

This interface provides missions that need to be cleared before starting the game. Each stages has different missions, both in terms of time and in terms of scores that must be met. The results of the Interface can be seen in Fig.7.

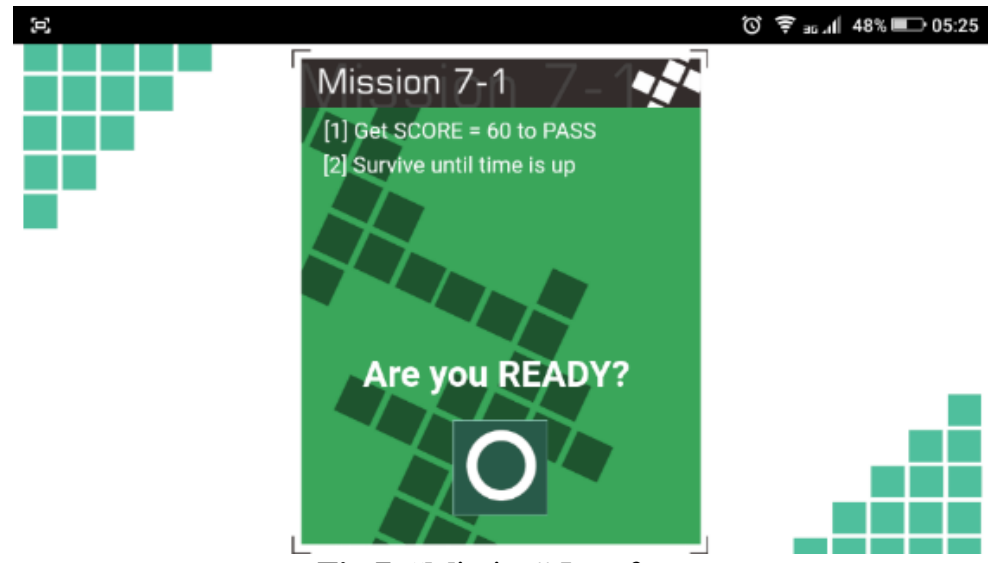

Fig.7. "Mission" Interface

(7) "Gameplay" Interface

This interface focuses more on the game environment that will be played by players. On the left side there are 3 small green boxes with the words "Life", which means that the player has 3 lives or 3 chances at the beginning of the game. Players will lose 1 life if they answer wrongly. On the upper middle side there is a scoreboard with the words "Correct" or "Wrong". On the scoreboard, the black box is the player's score, while the white box is the score that the player must meet to win. 
The writing "Correct" or "Wrong" pop-up will appear when the player touches 1 of 3 transparent boxes in the left, center and right of the screen. On the upper right side of the screen there is a Pause button which when touched will stop the game temporarily. Under the layaer there is 1 box consisting of a time box on the left side and a question box on the right side. For more details the interface can be seen in Fig. 8 .

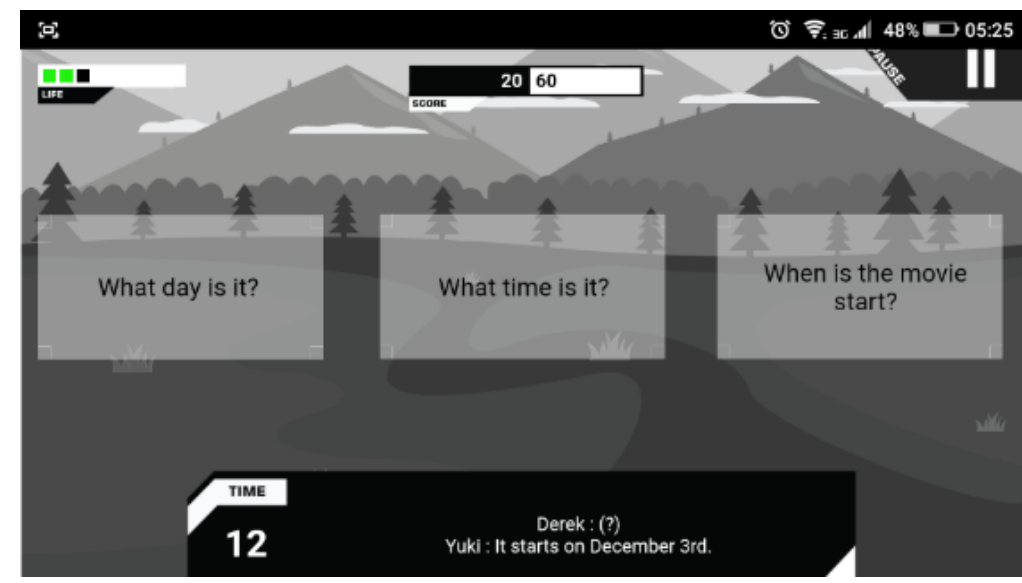

Fig.8. "Gameplay" Interface

(8) "Pause" Interface

This interface presented in Fig.9 provides a choice of material to be selected by the player. Each material that is available is material based on the grade chosen by the previous player, and the entire material available has been adapted to the junior high school curriculum standard. Same as "Grade", the "Stage" menu is also filled with the "Coming Soon" box which will be updated in the future.

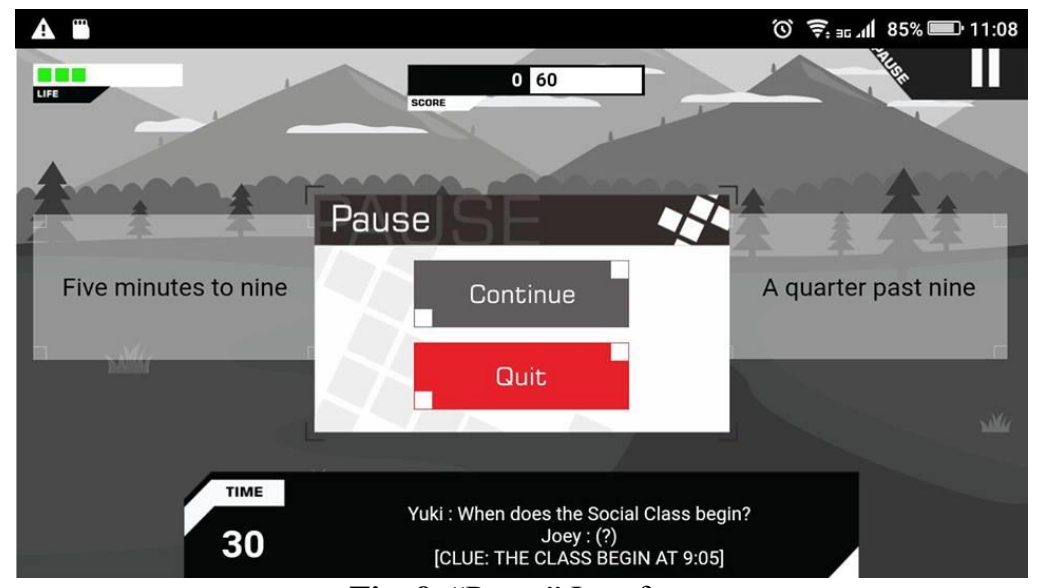

Fig. 9. "Pause" Interface

(9) “Game Over” Interface

This interface will appear if the player's ran out of lives or the player cannot complete the mission with the specified time. The interface can be seen in Fig.10. 


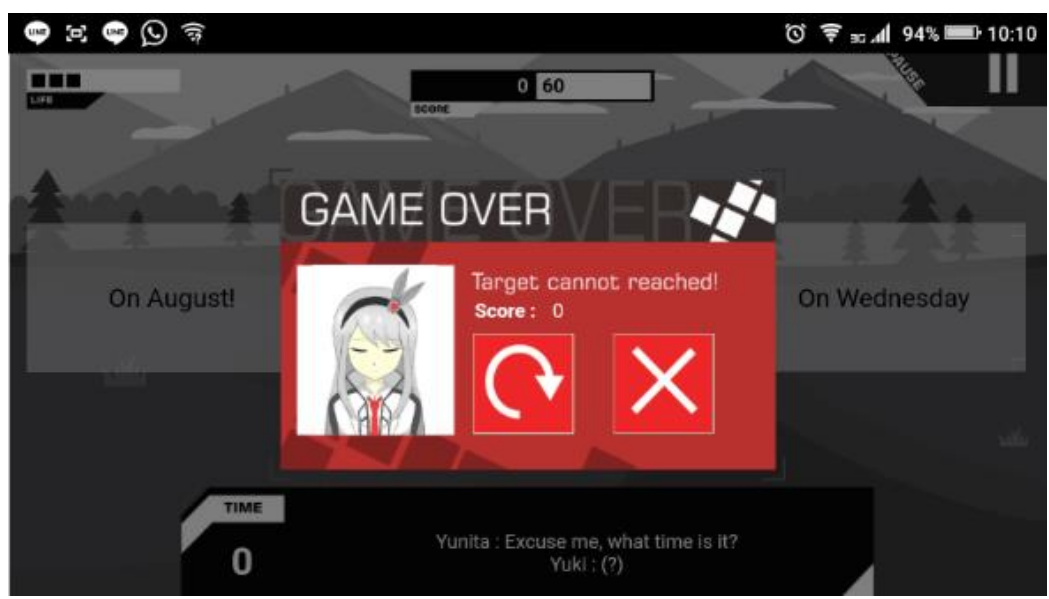

Fig. 10. "Game Over” Interface

(10) "You Win" Interface

This interface will appear if the player can complete the mission specified in the "Mission" Interface. The interface can be seen in Fig.11.

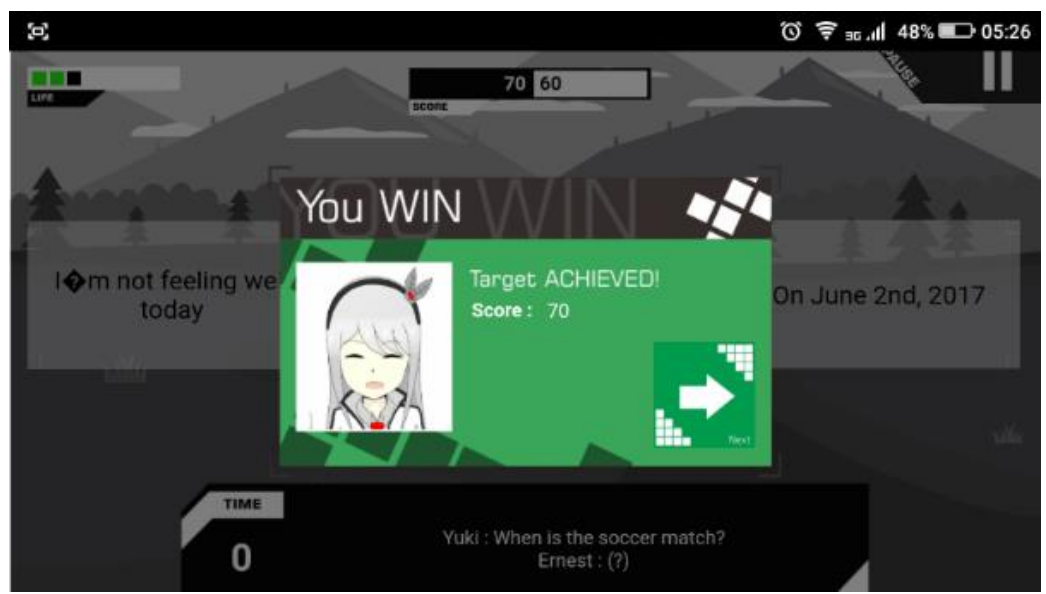

Fig. 11. "You Win" Interface

\subsection{Testing Evaluation}

The evaluation of testing includes alpha testing and beta testing. The detail explanation of the testing procedures is presented below.

(1) Alpha Testing

Alpha testing is done using a black box testing design that is done internally [6]. The arrangement of the black box testing plan can be seen in Table 1. From the design of the black box testing that has been compiled as above, the results of the testing of each smartphone device can be seen in Table 2 . 
Table 1. The black box testing plan

\begin{tabular}{clc}
\hline No. & \multicolumn{1}{c}{ Testing Detail } & Testing Type \\
\hline 1. & See Story & Black box \\
2. & Choose Stage & Black box \\
3. & Choose Grade & Black box \\
4. & See Credit & Black Box \\
5. & Enter Gameplay System & Black box \\
\hline
\end{tabular}

Table 2. Black Box Testing Results

\begin{tabular}{clccc}
\hline \multirow{2}{*}{ No. } & \multicolumn{2}{|}{ Testing Detail } & \multicolumn{3}{c}{ Testing Results } \\
\cline { 3 - 5 } & \multicolumn{1}{c}{ Coolpad Max } & Andromax A2 & Oppo F5 \\
\hline 1. & See Story & Succeed & Succeed & Succeed \\
2. & Choose Stage & Succeed & Succeed & Succeed \\
3. & Choose Grade & Succeed & Succeed & Succeed \\
4. & See Credit & Succeed & Succeed & Succeed \\
5. & Enter Gameplay System & Succeed & Succeed & Succeed \\
\hline
\end{tabular}

(2) Beta Testing

Beta testing is done by involving external examiners, who in this case are respondents from Purwokerto Middle School as the subject of research. The number of respondents involved in this study was 22 respondents who as a whole were students of Purwokerto Middle School.

All of these respondents were distributed questionnaires containing questions based on Jakob Nielsen's usability theory [7] and following the standard Questionnaire for User Interface Satisfaction (QUIS) [8]. The questionnaire design that is distributed to respondents can be seen in Table 3. The results of the data obtained from the 24 respondents can be seen in the following graph presented in Fig 12.

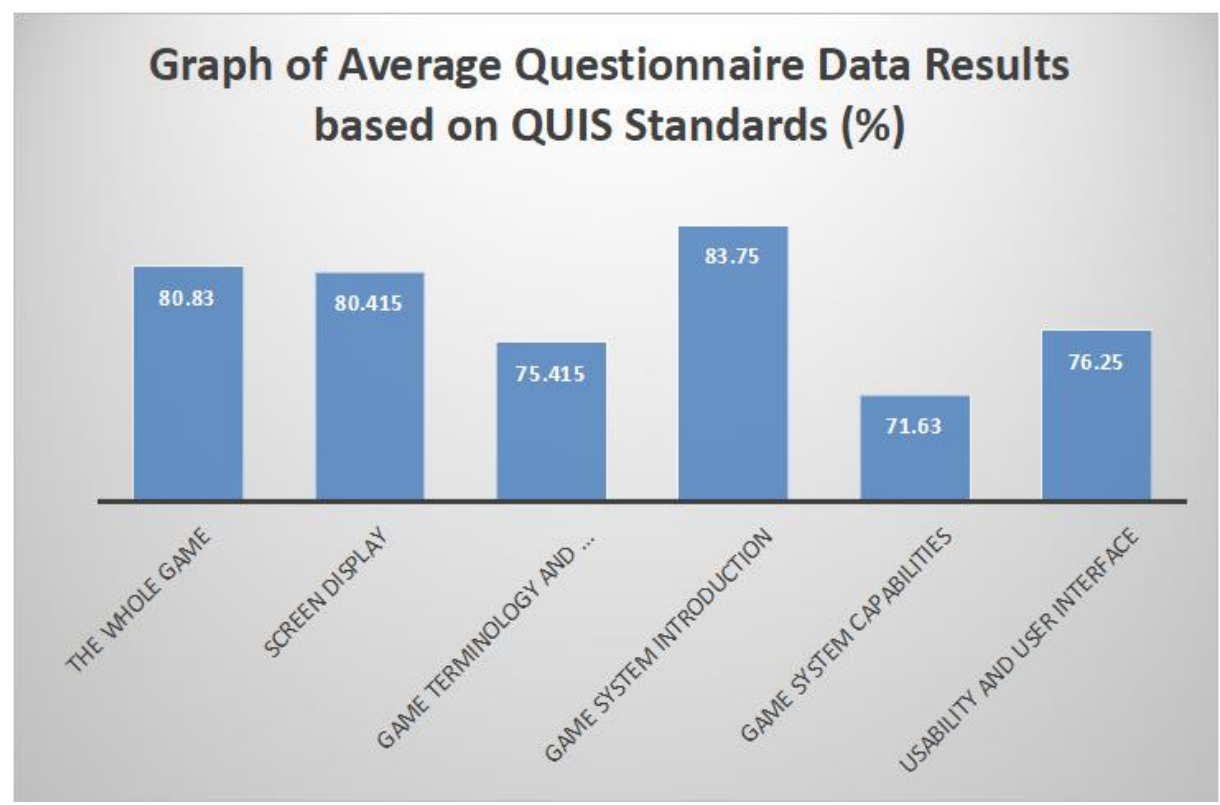

Fig.12. Graph of Average Questionnaire Data Results based on QUIS Standards 
Journal of Engineering and Applied Technology

Vol. 1, No. 1, March 2020, pp. 30-42

Table 3. Detailed Testing Questions

\begin{tabular}{|c|c|}
\hline No. & Questions \\
\hline \multicolumn{2}{|c|}{ The Whole Game } \\
\hline 1. & The game is interesting \\
\hline 2. & The game is easy to use \\
\hline 3. & The game is very satisfying \\
\hline 4. & $\begin{array}{l}\text { After using this game, you will find it helpful to learn English properly and it is easy to } \\
\text { understand }\end{array}$ \\
\hline \multicolumn{2}{|c|}{ Screen Display } \\
\hline 5. & The text on the application is easy to read \\
\hline 6. & The order of the screens is clear and does not confuse the user \\
\hline \multicolumn{2}{|c|}{ Game Terminology and Information } \\
\hline 7. & The suitability of the game material with the material taught in school \\
\hline 8. & The language used is understandable \\
\hline 9. & Quiz questions are easy to answer \\
\hline \multicolumn{2}{|c|}{ Game System Introduction } \\
\hline 10. & The gameplay is easy to understand \\
\hline 11. & There is a tutorial on playing the game \\
\hline 12. & Can remember existing buttons and their uses \\
\hline 13. & Can recall the Gameplay system after not being used for a long time \\
\hline \multicolumn{2}{|c|}{ Game System Capabilities } \\
\hline 14. & The game can run fast \\
\hline 15. & The time given in the Gameplay system is appropriate \\
\hline 16. & Players can correct mistakes if an error occurs \\
\hline \multicolumn{2}{|c|}{ Usability and User Interface } \\
\hline 17. & The use of color is good. \\
\hline 18. & Games can display notifications/messages well \\
\hline
\end{tabular}

Based on the graph in Figure 12 above, the following information can be drawn.

(1) As a whole game system, it can be concluded that the game application is well accepted by junior high school students.

(2) For screen display, it can be concluded that the available screen displays and the order of the screens can be well understood by the user.

(3) For the game technology and information section, the English Challenge game application is good enough, but it still leaves certain notes, especially in the suitability of the material which according to respondents is still not good enough.

(4) For the introduction of the game system, respondents can make adjustments well. Although no "help" button can guide respondents in using the application.

(5) For the game system capabilities, it still needs better adjustments. This can be seen in Figure 12 which says that the graph "Game System Capability" is in the lowest order among the others. In general, the main problem lies with errors/bugs and timing adjustments. 
Journal of Engineering and Applied Technology

Vol. 1, No. 1, March 2020, pp. 30-42

(6) For usability and user interface, respondents said it was good enough. This means the game is quite capable of interacting with users, but it needs additional adjustments so that the game can interact better.

\section{Conclusion}

Based on the data obtained from the questionnaire, it can be concluded that the English Challenge game application is quite accepted by the community, especially junior high school students who are still studying English language material in their schools. However, to be able to provide even better interaction, it is necessary to develop and add features in the game, with the aim that users can understand English more easily. Besides, this English Challenge game was designed for normal users, not users with special needs like blind users or visually impaired users. It would be better if this game can be developed further. By providing new interactive features such as multimodal earcon interaction [9] might lead to the possibility that this game can be also available for blind or visually impaired users. So, they can also learn English through the English Challenge game. In addition, adding more types of questions besides multiple choices, such as short essays, might enrich the user's learning experience. The implementation of an automatic essay scoring system [10,11] can be used to evaluate the short answer of the player in this game.

\section{References}

[1] A. P. Septy, "Assumptions and evidences about introducing English in Indonesian primary schools," International Journal: Language, Society and Culture. 2000.

[2] EF, "Indeks Kecakapan Bahasa Inggris EF." [Online]. Available: https://www.ef.co.id/epi/regions/asia/indonesia/. [Accessed: 22-Mar-2018].

[3] L. P. Siregar, "Orang Inggris Belajar Bahasa Inggris," 2014. [Online]. Available: http://www.bbc.com/indonesia/blogs/2014/03/140327_blog_bahasa. [Accessed: 22-Mar-2018].

[4] I. N. Arifah, "Pengajaran Bahasa Inggris di Indonesia Terlalu Kaku," 2014. [Online]. Available: http://www.radioaustralia.net.au/indonesian/2014-05-30/pengajaran-bahasa-inggris-diindonesia-terlalu-kaku/1318670. [Accessed: 23-Mar-2018].

[5] R. Ramadan and Y. Widyani, "Game development life cycle guidelines," in 2013 International Conference on Advanced Computer Science and Information Systems (ICACSIS), 2013, pp. 95100.

[6] L. Copeland, A Practitioner's Guide to Software Test Design. Boston, London: Artech House Publishers, STQE Publishing, 2004.

[7] J. Nielsen, "Usability 101: Introduction to Usability," Nielsen Norman Gr., p. Articles, 2012.

[8] K. L. Chin, J.P., Diehl, V.A., Norman, "Questionnaire for User Interface Satisfaction,” Dev. an Instrum. Meas. User Satisf. Human-Computer Interface, no. 1988, p. ACM CHI'88 Proceedings, 213-218, 1988.

[9] I. A. Bustoni, I. Hidayatulloh, and A. Azhari, "Multidimensional Earcon Interaction Design for The Blind: a Proposal and Evaluation," in 2018 International Seminar on Research of Information Technology and Intelligent Systems (ISRITI), 2018, no. November, pp. 21-22.

[10] G.B. Herwanto, Y. Sari, B.N. Prastowo, M. Riasetiawan, I.A. Bustoni, and I. Hidayatulloh, "UKARA: A fast and simple automatic short answer scoring system for Bahasa Indonesia," in 
Journal of Engineering and Applied Technology

Vol. 1, No. 1, March 2020, pp. 30-42

2018 Proceeding Book of 1st International Conference on Educational Assessment and Policy, $2,48-53$.

[11] G.B. Herwanto, Y. Sari, B.N. Prastowo, M. Riasetiawan, I.A. Bustoni, I. Hidayatulloh, and T.B. Adji, "A Proposed Framework for Essay Answer Processing based on Computational," in 2018 Proceeding Book of 1st International Conference on Educational Assessment and Policy, $2,54-58$. 